\title{
LA CODIFICACIÓN COMO PROGRAMA CONSTITUCIONAL EN FRANCIA, ESPAÑA E IBEROAMÉRICA DURANTE EL SIGLO XIX*
}

\author{
CODIFICATION AS CONSTITUTIONAL PROGRAMME IN \\ NINTEENTH CENTURY FRANCE, SPAIN AND LATIN AMERICA
}

\section{Alejandro Guzmán Brito **}

I. Un artículo 258 de la Constitución de Cádiz disponía lo siguiente: "El código civil y criminal y el de comercio serán unos mismos para toda la Monarquía, sin perjuicio de las variaciones que por particulares circunstancias podrán hacer las Cortes". No disponemos de noticias directas que nos señalen cuál hubo de ser la fuente en que los constituyentes gaditanos se inspiraron para redactar esta disposición. Por mi parte, me atrevo a sugerir que la fuente inmediata fue la Constitución de Bayona de $1808^{1} \mathrm{y}$ que su fuente mediata fue la Constitución francesa de 1791 .

a) En la primera de las citadas había cuatro disposiciones concernientes a la codificación, como siguen:

\footnotetext{
Este trabajo forma parte del Proyecto Anillo de Investigación Asociativa en Ciencias Sociales, "Estudios Histórico-Dogmáticos de Derecho Patrimonial Privado: una mirada a los artículos de los Libros II y IV del Código Civil de Chile", SOC 1111, de CONICYT.

** Profesor de Derecho en la Pontificia Universidad Católica de Valparaíso.

1 "Constitución dada en Bayona el 6 de julio de 1808 aceptada el 7 de julio del mismo año por la Diputación general reunida en la misma ciudad de Bayona”, en Actas de la Diputación General de Españoles que se juntó en Bayona el 15 de junio de 1808 en virtud de convocatoria expedida por el gran duque de Berg como lugarteniente general del reino y la Junta Suprema de Gobierno con fecha 19 de mayo del mismo año (1874) (Madrid, Imprenta y Fundición de J. A. García) pp. 119-128.
}

i) La primera era el inciso $2^{\circ} \mathrm{del}$ artículo 82, incluido en el título $9^{\circ}$ : De las Cortes, que rezaba así: "[Inciso $1^{\circ}$ ] La ley fijará de tres en tres años la cuota de las rentas y gastos anuales del Estado, y esta ley la presentarán oradores del Consejo de Estado a la deliberación y aprobación de las Cortes./ [Inciso $2^{\circ}$ ] Las variaciones que se hayan de hacer en el Código civil, en el Código penal, en el sistema de impuestos o en el sistema de moneda, serán propuestas del mismo modo a la deliberación y aprobación de las Cortes"2. Esta norma, a su vez, provenía del "Proyecto de estatuto constitucional presentado de orden de S.M. I. y R. Napoleón, emperador de los franceses y rey de Italia a la Junta de Españoles celebrada en Bayona a 20 de junio de 1808 "3.

ii) En seguida estaba el artículo 96 dentro del título 11\%: Del orden judicial, y decía: "Las Españas y las Indias se gobernarán por un solo Código de leyes civiles y

2 En Actas de la Diputación General de Españoles (1874) p. 124.

3 Actas de la Diputación General de Españoles (1874) pp. 53-60. El artículo 77 del "Proyecto" rezaba así: "Las variaciones notables que se hayan de hacer en el Código civil, en el Código penal, en el sistema de impuestos o en el sistema de moneda, serán propuestas para la deliberación de las Cortes por oradores del Consejo de Estado" (Actas de la Diputación General de Españoles (1874) p. 57). No existía el inciso $1^{\circ}$ del que después fue el artículo 82 . 
criminales" ${ }^{4}$. La disposición asimismo venía del "Proyecto"s.

iii) Comparecía después el artículo 113, también sito en el ya mentado título $11^{\circ}$, cuyo texto expresaba: "Habrá un solo código de Comercio para España e Indias". Del mismo modo su antecedente se encuentra en el "Proyecto"7.

iv) En fin estaba el artículo 144 localizado en el título 13: Disposiciones generales, que decía: "Los fueros particulares de las provincias de Navarra, Vizcaya, Guipúzcoa y Álava se examinarán en las primeras Cortes, para determinar lo que se juzgue más conveniente al interés de las mismas provincias y al de la nación" ${ }^{8}$. En este caso falta todo antecedente en el "Proyecto"; pero de la lectura de las actas se desprende que la norma fue introducida en el texto final para hacer obsequio a las observaciones que había formulado el diputado por Guipúzcoa, José María de Lardizábal y Orior $^{9}$, en orden a destacar

4 Actas de la Diputación General de Españoles (1874) 125.

5 Actas de la Diputación General de Españoles (1874) p. 58: Artículo 87: "La España se gobernará por un solo código de leyes civiles"; como se ve, la palabra "España" fue cambiada a "las Españas", y le fueron añadidas las expresiones: "y las Indias" y " $y$ criminales”. Esta última añadidura fue propuesta por los diputados Mariano L. de Urquijo y Vicente Alcalá Galiano (Actas de la Diputación General de Españoles (1874) pp. 83 y 85).

6 Actas de la Diputación General de Españoles (1874) p. 126.

7 Actas de la Diputación General de Españoles (1874) p. 59: Artículo 100: "Habrá un solo código de comercio para todo el reino". Se sustituyó pues "todo el reino" por "España e Indias".

8 Actas de la Diputación General de Españoles (1874) p. 128.

9 Véase la "Exposición hecha al emperador sobre el proyecto de constitución por el Sr. D. José María de Lardizábal y Orior, representante de la provincia de Guipúzcoa”, en Actas de la Diputación General de Españoles (1874) pp. 107-108. las peculiaridades de Guipúzcoa, sobre todo por lo que atañía a sus usos, costumbres, que parecían incompatibles con la nueva constitución. Remitiendo la determinación de lo que se juzgue conveniente a las Cortes, se creyó oportuno ampliar la consideración a las demás provincias vascas, sin limitar la norma entonces redactada a solo Guipúzcoa.

b) Cuando se examina el artículo 258 de la Constitución de Cádiz, se observa que él viene a ser una suerte de compendio de las cuatro normas de la Constitución de Bayona

La enumeración de códigos que hace Cádiz: "El código civil y criminal y el de comercio" es reflejo de la enumeración combinada de los artículo 96: "Código de leyes civiles y criminales" y 113: "Código de Comercio" que ofrece Bayona. A su turno, la idea de que esos tres códigos "serán unos mismos para toda la Monarquía” presente en Cádiz, es reflejo de la misma idea preexistente en los citados artículos 96: "Las Españas y las Indias se gobernarán por un solo Código [...]", y 113: "Habrá un solo código [...] para España $e$ Indias" de Bayona. La referencia concreta a "España e Indias" fue abstraída con recurso a la expresión "toda la Monarquía". En fin, la cláusula final del artículo 258 de Cádiz: "sin perjuicio de las variaciones que por particulares circunstancias podrán hacer las Cortes" también es una abstracción y una generalización de la muy concreta norma del artículo 144 de Bayona: "Los fueros particulares de las provincias de Navarra, Vizcaya, Guipúzcoa y Álava se examinarán en las primeras Cortes, para determinar lo que se juzgue más conveniente al interés de las mismas provincias y al de la nación", seguramente irradiada también por el inciso $2^{\circ}$ del artículo 82 de Bayona: "Las variaciones que se hayan de hacer en el Código civil, en el Código penal [...], serán propuestas del mismo modo a la deliberación y aprobación 
de las Cortes"; a lo cual me mueve a pensar el término "variaciones" que, como se ve, es común a los artículos 258 de Cádiz y 82 de Bayona.

c) Ahora bien, la Constitución francesa de septiembre de 1791, en el número 3, inciso final de su título $1^{\circ}$ : Dispositions fondamentales garanties par la Constitution, decía lo siguiente: "Il sera fait un code des lois civiles communes à tout le Royaume" 10 . La disposición había sido precedida de otra algo semejante contenida en un Décret sur l'organisation judiciaire de 24 de agosto de 1790, emanado por la Assemblée Nationale Constituant, el artículo 19 de cuyo título $2^{\circ}$ expresaba: "Les lois civiles seront revues et reformées par les législatures; et il sera fait un code générale de lois simples, claires et appropriées à la constitution" 11 .

Ambas disposiciones eran reflejo de las reiteradas y coincidentes peticiones de elaborar un código unitario o único de Derecho para todo el reino, contenidas en los "cahiers de doléance" de los tres estados, hechos llegar al Rey durante el período de preparación de los Estados generales de $1789^{12}$. Puede decirse que esta aspiración era opinión común en Francia y no es extraño entonces que la Assemblée Nationale Constituant se haya hecho eco de ella en las dos ocasiones antes recordadas y, sobre todo, que haya elevado la tarea al rango de un mandato constitucional. Lo mismo

10 En Duguit, L., Monnier, H., Bonnard, R. (1952): Les Constitutions et les principales lois politiques de la France depuis 1789 (7a edición, Paris, Librairie Générale de Droit et de Jurisprudence) p. 5.

11 En Hélie, F. A. (1879): Les Constitutions de la France (Paris) p. 148.

12 Sobre esto: Wilhelm, Walter (1967): "Gesetzgebung und Kodifikation in Frankreich im 17. und 18. Jahrhundert", en Ius Commune, 1, Frankfurt am Main, cap. V: pp. 257-262. explica que ese mandato haya sido reiterado poco después. Primeramente, en el "Plan de constitution présentée a la Convention Nationale", en febrero de 1793 por el grupo de los Girondinos, por lo cual suele conocérselo como "Proyecto de constitución girondina”. En el artículo 1 de la sección $1^{\text {a }}$ de su título $10^{\circ}$ (equivalente al artículo 266 en una numeración corrida puramente mental), se decía: "Il y aura un code des lois civiles et criminelles uniformes pour toute la République"13. Y seguidamente en el Acte constitutionnel de 24 de junio de 1793, que suele citarse como "Constitución jacobina" de 1793, cuyo artículo 85 declaraba: "Le code des lois civiles et criminelles est uniforme pour toute la République"14, aunque en esta última norma no se mandaba confeccionar un código, pues solo se ordenaba que él fuese uniforme.

Esta tradición francesa no pudo menos que influir en espíritu de los redactores del "Proyecto de estatuto constitucional" presentado en Bayona, cuyo principal artículo sobre la materia, el 87, rezaba, como vimos, así: "La España se gobernará por un solo código de leyes civiles", convertido en el artículo 96 en la Constitución promulgada en la misma Bayona en 1808: "Las Españas y las Indias se gobernarán por un solo Código de leyes civiles y criminales", sin perjuicio de haber dado pie a las demás normas sobre la misma materia esparcidas en la Constitución de Bayona, que antes vimos.

II. El texto del artículo 258 de la Constitución de Cádiz, que vuelvo a transcribir: "El código civil y criminal y el de comercio serán unos mismos para toda la Monarquía, sin perjuicio de las variaciones que

13 Duguit et al. (1952) p. 54.

14 Duguit et al. (1952) p. 70. 
por particulares circunstancias podrán hacer las Cortes", merece algunas observaciones.

a) Es evidente que el acento de esta disposición cae sobre la frase: "serán unos mismos para toda la Monarquí". La idea que estaba en el fondo de la norma consistía en imponer la unidad legislativa en el territorio de la Monarquía y abolir la diversidad o variedad jurídica existentes entre sus territorios ${ }^{15}$; no se buscaba tanto imponer, pues, la codificación en sí. Ya era así en los precedentes de Bayona y franceses. El artículo 96 de la Constitución de Bayona, como se recordará, decía: "Las Españas y las Indias se gobernarán por un solo Código de leyes civiles y criminales". El punto central de la disposición está marcado por "se gobernarán por un solo Código". Lo propio se ve en Francia, pues en su Constitución de 1791 se trata disponer "un code des lois civiles communes à tout le Royaume"; en el proyecto girondino de un "code des lois uniformes pour toute la République" y lo mismo y con iguales palabras es en la Constitución de 1793. En Francia, pues, no se intentaba tanto establecer la codificación en sí, cuanto de superar la diversidad jurídica, implicada en la existencia de un número muy elevado de coutumes locales y regionales.

b) La forma de expresión contenida en el artículo 258 de la Constitución de Cádiz: "el código civil y criminal y el de comercio" resultaba ambigua. Desde luego podía aludir a "código" en el sentido moderno, que a la fecha estaba plasmado y representado por el modelo internacional del Code Civil de 1804 y los cuatro más que le siguieron en los años sucesivos sobre las materias mercantil, penal,

15 Sobre el tema a través del constitucionalismo español, véase: Fernández Álvarez, Antón Lois (2012): "El mandato de unificación jurídica y la constitución española”, en Revista de Estudios Histórico-Jurídicos, 34: pp. procesal civil y procesal penal. Pero también podía significar sin más "legislación civil, criminal y de comercio", aunque no fuera bajo la forma codificada al estilo moderno. En el temprano siglo XIX, el significado del término "código" aun no había sido decantado y asentado en la denotación de cuerpos unitarios de Derecho, confeccionados de acuerdo con unos cánones que habían quedado más o menos configurados a impulsos del Iusnaturalismo y la Ilustración, pero todavía no llevados a la práctica más que por el Allgemeines Landrecht für de preussischen Staaten prusiano de 1784, el Code Civil de 1804 y el Allgemeines Bürgerliches Gesetzbuch austriaco de 1811. En España, al menos, la voz "código" solió aplicarse con mucha frecuencia a los viejos cuerpos jurídicos de la Edad Media, como el Fuero Real o las Partidas y a las compilaciones de leyes de la Época Moderna, como las "Ordenanzas Reales de Castilla" u "Ordenamiento de Montalvo", la Recopilación de leyes de Castilla, llamada "Nueva Recopilación", y aun la Novísima Recopilación de Leyes de España ${ }^{16}$, a ninguno

16 Burriel, Andrés Marcos [1719-1762]: "Carta del padre Burriel a don Juan Amaya, de 30 de septiembre de 1751 ", en Cartas eruditas y críticas del P. Andrés Marcos Burriel de la extinguida Compañía de Jesús. Dalas a luz don Antonio Valladares de Sotomayor (Madrid, Imprenta de don Blas Román, s.d. [pero 1755]) p. 201: “'Importará a un letrado español [[...] ] saber bien [[...] ] cuáles son los códigos de leyes patrias, y cuál es el orden de preferencia que tienen entre sí”; Vizcaíno Pérez, Vicente (1784): Compendio del derecho público y común de España o de las leyes de las Siete Partidas colocado en orden natural (Madrid, Joaquín Ibarra) p. xvi: "El código de las Partidas"; Vizcaíno Pérez (1784): “Todos se alarmaron y miraron este código [las Partidas] como una novedad"; xvii: "La publicación del código más metódico que tiene Castilla [las Partidas] se reservaba para el reinado de D. Alfonso XI"; JORDÁN DE Asso, Ignacio [1742-1814] - de Manuel y Rodríguez, Miguel [s. XVIII], Instituciones del Derecho civil de Castilla $5^{\text {a }}$ edición, Madrid, Imprenta de Ramón Ruiz, 1792, en una suerte de prólogo no titulado así 
de los cuales cuerpos podía convenir la aplicación de la palabra "código", tomada esta voz en su sentido ilustrado. Por lo demás, se puede observar que cuando un autor quería aludir a una obra legislativa de nuevo cuño, la expresión más recurrida era "cuerpo de leyes" y no precisamente "código". En tales circunstancias es muy comprensible que este último término haya podido ser empleado a veces para referir sin más un sector de la legislación o incluso a toda ella. En este sentido, por ejemplo, resulta indiciario que Francisco Martínez Marina (1754-1833) comente así el fracaso de las peticiones contenidas en el codicilo de 1504 otorgado en Medina del Campo por Isabel I de Castilla, en orden a encargar al rey Fernando su marido y demás herederos, que manden reducir a un cuerpo las leyes del Fuero, los ordenamientos y las pragmáticas del Reino; y dice al respecto: "No se cumplieron por entonces los

ni de ninguna otra manera, p. sin número, pero tercera, con referencia a la Ley I de Toro, dice que ella: "declara con expresión cierta el orden de alegación, prueba y valimiento que han de tener las leyes de los diferentes códigos civiles del Reino"; Jovellanos, Gaspar Melchor de [1744-1811], "Carta al doctor Prado, del gremio y claustro de la Universidad de Oviedo sobre el método de estudiar el Derecho", en Biblioteca de autores españoles desde la formación del lenguaje hasta nuestros días, Madrid, Cándido Nocedal, 1859, L: Obras publicadas e inéditas de don Gaspar Melchor de Jovellanos, p. 147, con referencia al libro titulado Sacrae Themidis Hispanae Arcana de Juan L. Cortés, pero publicada plagiariamente por Gerardo Ernesto de Frankenau en 1703, dice "Esta obra $[[\ldots]]$ contiene muy llenas y curiosas noticias acerca del origen de nuestros códigos"; Martínez, Francisco [1754-1833], Ensayo histórico crítico sobre la legislación y principales cuerpos legales de los reinos de León y Castilla, 1808, $3^{\mathrm{a}}$ edición, Madrid, Imprenta de la Sociedad Literaria y Tipográfica 1845 , p. 434: "Al cabo [[...] ] llegó a verificarse la formación del suspirado código legislativo, y se imprimió en el año de 1567 con el título de Nueva Recopilación” bellos deseos de la reina Católica ni tuvo efecto la proyectada reforma del código legislativo" 17.

En síntesis, pues, el sentido del artículo 258 de la Constitución de Cádiz que parece como más auténtico es el de imponer una legislación civil, penal y mercantil común a toda la Monarquía, es decir, a todas sus partes o secciones tanto de la península como de las Indias. Que ello hubiera de ser bajo la forma de cuerpos de Derecho a la moderna o incluso a la antigua, eso no tenía tanta importancia como la unificación.

III. La Constitución de Cádiz ella misma fue una carta concebida para toda la Monarquía; también por ende para las Indias. Procedía pues que se la proclamase y jurase en los diversos reinos y provincias de América; lo cual efectivamente acaeció en varios de ellos. Pero no es nuestra tarea estudiar las vicisitudes de la recepción de aquella Constitución en América ${ }^{18}$; y solo nos limitaremos a verificar qué influjo pudo tener en cuanto portadora de un programa de unificación jurídica a través de la emisión de una legislación que denominó con recurso a la palabra "código".

Desde luego, la posibilidad de que el programa unificador de Cádiz haya podido influir en los antiguos reinos y provincias

17 Martínez Marina, Francisco [1754-1833] (1808): Ensayo histórico crítico sobre la legislación y principales cuerpos legales de los reinos de León y Castilla ( 3 a edición, Madrid, Imprenta de la Sociedad Literaria y Tipográfica) p. 434.

18 Sobre la Constitución de Cádiz en América: Stoetzer, Carlos (1966): El pensamiento político en la América española durante el período de la Emancipación. 1789-1825 (Madrid, Instituto de Estudios Políticos) II: pp. 223 ss.; García Laguardia, Jorge y otros (1987): La Constitución de Cádiz y su influencia en América (San José, Capel) 1987. Cfr. García Laguardia, Jorge (1994): Centroamérica en las Cortes de Cádiz ( $3^{\text {a }}$ edición, México, Fondo de Cultura Económica). 
de la Corona española en América es muy remota, porque la diversidad y variedad jurídicas que la carta gaditana pretendía superar no existió en esos territorios, los cuales estaban regidos por un ordenamiento tendencialmente el mismo para todos ellos ${ }^{19}$. En el orden del Derecho privado, procesal y penal, las Partidas y el Fuero Real eran las fuentes predominantes y esos tres cuerpos regían en todas las Indias. Si hubo algunas modificaciones, ellas estaban recogidas en la "Nueva Recopilación" de 1567 o en la Recopilación de las leyes de las Indias, de 1680 o, a fines de la época hispánica, en la Novisima Recopilación de leyes de Castilla, de 1804, cuerpos esos que asimismo tuvieron vigencia general en América. La legislación particular que hubo ahí fue la emanada por los órganos capaces de formular normas con sede en las distintas secciones territoriales indianas y para ellas, como los virreyes o los gobernadores o los cabildos; o bien emanada de los órganos centrales de la Monarquía como el Consejo de Indias o el rey mismo. Pero esa legislación prácticamente no tocó las ramas jurídicas antes mencionadas y normalmente se refería al Derecho de policía o al que hoy llamamos Derecho administrativo. En todo caso, su frondosidad no autoriza ni lejanamente a hablar de particularismo, diversidad o variedad en la legislación. De hecho, después de su independencia, América nunca más ha conseguido gozar de una unidad jurídica

19 En este trabajo reformulo el tema de las relaciones entre la Constitución de Cádiz de 1812 y la codificación en Iberoamérica y hasta rectifico algunos puntos en relación con lo escrito en GuZMÁn BRITO, Alejandro (2000): La codificación civil en Iberoamérica. Siglos XIX y XX (Santiago, Editorial Jurídica de Chile) $\$$ 18,5: pp. 231-237 = Guzmán Brito, Alejandro (2006) Historia de la codificación iberoamericana (Cizur Menor, Pamplona, Navarra, Thomson- Aranzadi) $\$ 7$, V: pp. 96-100. como la que disfrutaba en tiempos de la Monarquía. En tales circunstancias, la idea de propender al establecimiento de una misma y única legislación en el interior de cada república novísimamente formada no podía constituir ninguna aspiración que se fundara en alguna realidad contraria.

En las nuevas naciones desgajadas del tronco común el problema era otro. Ese problema queda suficientemente configurado cuando el observador se atiene a la difundida y persistente crítica a que fue sometido el Derecho castellano-indiano heredado por cada nuevo Estado de la antigua Monarquía. Esta crítica, que se encuentra ampliamente documentada $^{20}$ se la advierte repetida por doquier y desde muy temprano. Se la puede reducir a unos tópicos, que por lo general son los mismos que en Europa sirvieron para criticar el Derecho común por la jurisprudencia humanista no bien comenzado el siglo XVI. Ellos fueron: la multitud de leyes, su heterogeneidad, incoherencia y dispersión, la confusión producida por el exceso de comentarios por parte de los autores, la antigüedad del lenguaje empleado, el desuso de muchas de las partes del derecho heredado, todo lo cual producía dificultades para el conocimiento del derecho, incertidumbre e inseguridad en su aplicación y, en definitiva, una mala administración de la justicia, tema este último en el que las anteriores críticas normalmente desembocaban. Sin embargo, hubo un par de temas críticos relativamente originales. El primero se explica por el sentimiento de contraste entre la pasada sujeción a la Corona de España y el nuevo estado de soberanía ganado, y consistía en acusar que la legislación castellano-indiana heredada de

\footnotetext{
20 Sobre el particular, véase: GuZMÁn Brito (2000) pp. 189-196; cfr. pp. 218-224 = GuZMÁN Brito (2006) pp. 62-68, cfr. pp. 85-90.
} 
la primera y que, no obstante, por la fuerza de los hechos se debía continuar usando, había sido generada por un gobierno "despótico y feudal", que ya no existía en América, de modo que dicha legislación aún vigente se había puesto en desarmonía con la actual "constitución de la libertad". El segundo iba dirigido contra el Derecho patrio gestado por los nuevos Estados, en cuanto, por su carácter inorgánico, contingente y particular, había venido a aumentar la confusión preexistente en la legislación antigua, con el agregado de nuevas leyes que presentaban tales características.

En tales circunstancias, la reclamación de la reforma del Derecho no consistió, como se dijo, en la formulación de un Derecho único y común en el interior de cada nueva nación, sino simplemente en el reemplazo de la legislación antigua por una nueva. Ahora bien, históricamente, las independencias políticas de las antiguas secciones americanas de la corona de España prácticamente fueron coincidentes con la expansión del modelo codificador en Europa. Así como en orden del Derecho público esas secciones se hicieron soberanas coincidentemente con la aparición del modelo del constitucionalismo liberal-representativo, de donde que empezaran a proliferar en ellas las constituciones escritas, así también, en el orden del Derecho privado y del procesal y penal, nacieron ellas coincidentemente con la consolidación del modelo de la codificación. Ahora bien, lo mismo que en Europa, en América esta se presentó como el modelo destinado a superar los vicios de la legislación antigua, en cuanto la confección de códigos implicaba la elaboración de una legislación favorecida por unos rasgos que eran exactamente los contrarios a los vicios achacados a la vigente. Un código a la moderna se caracterizaría, en efecto, por contener pocas leyes, redactadas en un estilo claro, preciso, desnudo de toda retorica y en lenguaje vernáculo, que deberían quedar insertadas en un sistema u orden discernible y comprensible incluso para el común. Por cierto, el Code Civil de 1804 -según se pensaba y decía- era el caso que más perfectamente había trasuntado aquellos caracteres; de donde que se haya constituido rápidamente en América, como había sido también en Europa, en el modelo más celebrado y más frecuentemente imitado, durante toda la primera mitad del siglo XIX.

De esta forma, en América resultaba más atractiva la idea de la codificación, en sí misma considerada, que aquella de la unificación jurídica. Si la Constitución de Cádiz, o tal vez la de Bayona, en cuanto portadoras de un programa de nueva legislación, pudieron haber ejercido algún influjo en América, ello solo pudo ser en cuanto esa nueva legislación asumía la forma de códigos, no en cuanto estaba destinada a unificar el ordenamiento jurídico y superara la diversidad y variedad del Derecho. Solo en un texto hemos hallado que se insistiera en la unidad de la legislación; lo cual se entiende, porque se trata de la Constitución Federal de Venezuela de 1864 , cuyo artículo 13 No 22 , en efecto, comprometía a los Estados federados "a tener para todos ellos una misma legislación sustantiva, civil y criminal'21. De todos modos es un caso muy excepcional, porque la idea no aparece antes ni vuelve a repetirse en Estados que, como Venezuela, adoptaron la forma federal.

De todos modos es muy difícil que los juristas y políticos americanos hayan obtenido de la Constitución de Cádiz o

21 En Las Constituciones de Venezuela (1985), con un "Estudio preliminar" de Brewer-Carías, Allan (Madrid, Centro de Estudios Constitucionales y otros) p. 414. 
de cualquier otra la idea de codificar. Esto parece evidente y no necesita ser abundado. Cosa distinta es la idea de un programa de codificación elevado a rango constitucional, de modo de revestirlo con la fuerza impulsora que se atribuye a las cartas constitucionales. En realidad a este punto queda recudido el posible influjo a la Constitución de Cádiz, no sin antes insistir que ese punto no tuvo su origen en ella, sino en Francia, en la Constitución de 1781 y que le llegó por el conducto de otro texto de origen francés, la Constitución de Bayona, de 1808, según vimos en su lugar.

IV. Ahora bien, cuando nos aplicamos a examinar los textos americanos concernientes, verificamos ya preliminarmente que la idea de una nueva legislación bajo la forma de código emergió antes de la promulgación de la Constitución de Cádiz, pero después de la de aquella de Bayona.

En un proyecto de Constitución para Chile que se redactó en 1811 y se publicó en 1813, aunque no fue aprobado, su artículo 21 parte $4^{\mathrm{a}}$ aludió débilmente, sin embargo, a la codificación, tal vez mentada bajo el término "legislación": "Concluidas estas comisiones o antes si es posible, se establecerá la de Legislación de la República, deducida de los principios de la Constitución [...]"22.

En Venezuela, también en 1811, su Congreso Constituyente, en sesión de 9 de marzo de ese año, acordó designar una comisión de ocho personas "[...] para que formasen un código civil y criminal, que tuviese por principal objeto la simplicidad y brevedad de los juicios y la recta y segura administración

22 En Letelier, Valentín (1887): Sesiones de los cuerpos legislativos de la República de Chile. 1811 a 1845 (Santiago, Imprenta Cervantes) I: pp. 242-243. de justicia"23; idea que incluso fue elevada de rango por el artículo 228 de la Carta Federal de 21 de diciembre de 1811, el cual disponía que: "Entretanto que se verifica la composición de un Código Civil y Criminal, acordado por el Supremo Congreso [...]"24.

Pero fue en los territorios del antiguo Virreinato de Nueva Granada, en la parte que habrían de integrar Colombia en el futuro, que diversos textos constitucionales hicieron referencia a la formación de nuevos códigos. La Constitución de Cundinamarca, en efecto, promulgada el 4 de abril de 1811, decía en su artículo 24 del título 60: "El primer cuidado del Cuerpo Legislativo será proceder a la indispensable reforma del Código 25 que nos rige, a fin de adaptarlo a la reforma del gobierno que se ha establecido; entretanto que se verifica esta reforma debe declararse y se declara dicho Código en toda su fuerza y vigor, en los puntos que directa o indirectamente no sean contrarios a esta Constitución" 26 . El artículo 7 No 3 del Acta de Federación de las Provincias Unidas de la Nueva Granada, de 27 de noviembre de 1811, reservaba a la Federación: "La formación de sus códigos civiles $y$ criminales" 27 . La norma cundinamarquesa inspiró la de otras constituciones particulares, como la del artículo 9 del capítulo 30, de la Constitución de la República de Tunja

23 Gazeta de Caracas, Vol. III, No 150, de 12 abr. 1811, transcrita por Parra Aranguren, Gonzalo (1974): Nuevos antecedentes sobre la codificación civil venezolana (1810-1862), como "Introducción" a La codificación de Páez, I: Código Civil de 1862 (Biblioteca de la Academia Nacional de la Historia, 15, Fuentes para la historia republicana de Venezuela, Caracas) p. xiii.

24 Venezuela, Const. de 1811, en las Constituciones de Venezuela (1985) p. 202.

25 En realidad, "código" significa aquí "legislación” y no tanto "código" en sentido moderno.

26 En Uribe Vargas, Diego (1974): Las constituciones de Colombia (Madrid, Ediciones Cultura Hispánica) I: p. 330.

27 Uribe Vargas (1974) p. 367. 
de 9 de diciembre de 1811, que decía: "Luego que lo permitan las circunstancias, deberá ocuparse [la Legislatura] en la formación de un sabio Código civil, y otro criminal [...]"28; norma esta repetida en el artículo 9 del título $3^{\circ}$, sección $1^{\text {a }}$ de la Constitución del Estado de Antioquía de 21 de marzo de $1812^{29}$. La antes citada de Cundinamarca lo está en el artículo 20 del título $6^{\circ}$ de la Constitución del Estado de Cartagena de Indias, de 5 de junio de 1812, que disponía: "Uno de los objetos principales que ocupará la atención del Cuerpo Legislativo será la revisión y reforma del Código que nos rige, a fin de acomodarlo al sistema de gobierno establecido" 30 ; y en el artículo 34 del título $4^{\circ}$ de la nueva Constitución de la República de Cundinamarca, de 18 de julio de 1812: "El primer objeto del Poder Legislativo será proceder a la indispensable reforma del Código que nos rige, a fin de adaptarlo a la forma de gobierno que se ha establecido; y entretanto que se verifica esta reforma se declara dicho Código en toda su fuerza y vigor, en los puntos que directa o indirectamente no sean contrarios a esta Constitución" 31 .

Todos estos textos novogranadinos, pues, fueron anteriores a la Constitución de Cádiz, de modo de resultar ostensible que el programa de una legislación bajo la forma de códigos que aquella contenía no los pudo influir.

V. La mayoría de los textos constitucionales iberoamericanos portadores de semejante programa, sin embargo, fueron posteriores a la Constitución de Cádiz; y pertenecieron a países variados.

\footnotetext{
28 Uribe Vargas (1974) p. 401.

29 Uribe Vargas (1974) p. 429.

30 Uribe Vargas (1974) p. 494.

31 Uribe Vargas (1974) p. 448.
}

Si atendemos a Chile, que fue en donde por vez primera vimos emerger el asunto en el recuento de textos anteriores a la Constitución gaditana, nos encontramos con el artículo 149 No 10 de la Constitución Política del Estado de Chile, promulgada en diciembre de 1823, se dijo, con respecto a la Corte Suprema: "Queda a su cargo el trabajo consultivo y preparatorio sobre los códigos legales del Estado, que concluirá en el término y forma que prefije el Senado"32. En el Proyecto de Constitución Federal para el Estado de Chile, presentado a la Legislatura en 1826, y no aprobado, su artículo 144 decía, volviendo al lenguaje de la "legislación": "Se crearán desde ahora una comisión que presente a la Legislatura Nacional un proyecto de legislación civil y criminal. [...]"33. En fin, artículo 46 de la Constitución Politica de Chile de 1828, declaró: "Son atribuciones exclusivas del Congreso: $1^{\circ} \mathrm{Ha}$ cer y mandar promulgar los códigos [...]"34.

En Venezuela, el artículo 87 No 1 de la Constitución de 1830, disponía ser atribución del Congreso "formar los códigos nacionales" 35 ; la norma se repitió posteriormente en los artículos 64 No 1 de la Constitución de 185836, 43 No 6 de la Constitución de $1864^{37}$ y 43 No 6 de la Constitución de $1874^{38}$.

Si ahora nos volvemos a los territorios de Nueva Granada, a los cuales perteneció la

32 En Valencia Avaria, Luis (1986): Anales de la República (2a edición, Santiago, Editorial Jurídica de Chile) 2a parte: p. 135 .

33 Proyecto de Constitución bajo un sistema federal presentado por la Comisión del Congreso con el informe de esta, Santiago, 1826.

34 En Valencia Avaria (1986) pp. 32-33.

35 En Uribe Vargas (1974) p. 342.

36 Uribe Vargas (1974) p. 387.

37 URibe Vargas (1974) p. 418.

38 Uribe Vargas (1974) p. 452. 
mayoría de los provenientes del período anterior, comparece el artículo 36 No 22 de la Constitución de la Colombia bolivariana, de 1830, el cual dispuso ser atribución exclusiva del Congreso "formar los códigos nacionales de toda clase" 39 , lo que hubo de ser repetido en el artículo 74 No 24 de la Constitución del Estado de Nueva Granada, de $1832^{40}$.

El artículo 211 de la Constitución llamada de Apatzingán (México), de 1814, ordenó mantener en vigor las antiguas leyes, mientras la soberanía nacional no formase el cuerpo de las nuevas ${ }^{41}$.

El artículo 106 de la Constitución peruana de 1823 dispuso: "Los códigos Civil y Criminal prefijarán las formas judiciales"; y su artículo 121 preveía la "organización de los códigos Civil, Criminal, Militar y de Comercio"42. Posteriormente la llamada Constitución Vitalicia de 1826, en su artículo 46 No 1, atribuía al Senado la facultad de "Formar los códigos civil, criminal, de procedimientos y de comercio y los reglamentos eclesiásticos" ${ }^{\prime 3}$. Todavía el artículo 131 de la Constitución de 1828, establecía algo semejante. Y, en fin, el artículo 11 transitorio de la Constitución de 1834, dispuso que "en la apertura de cada sesión anual presentará al Congreso la Corte Suprema el proyecto de uno de los códigos de la legislación, principiando por el civil'44.

\footnotetext{
39 Restrepo Piedrahita, Carlos (1995): Constituciones políticas nacionales de Colombia (2a edición, Bogotá) p. 110.

40 Restrepo Piedrahita (1995) p. 160.

41 González, Ma . del Refugio (1981): Estudios sobre la historia del derecho civil en México durante el siglo XIX (México, UNAM.) p. 87.

42 En Pareja, J. (1954): Las Constituciones del Perú (Madrid, Ediciones Cultura Hispánica) p. 439.

43 Pareja (1954) p. 473.

44 Pareja (1954) p. 577. Cfr. artículo 177, en donde se confirma la legislación vigente "hasta que se publiquen los códigos de legislación” (Pareja (1954) p. 574).
}

El artículo 29 No 2 de la Constitución de El Salvador, de 1824, señalaba ser atribución propia del Congreso: "Formar el código civil y criminal" ${ }^{35}$; y el artículo 20 de la de 1841 asignaba al Poder Legislativo: "[...] decretar los códigos de procedimiento y el civil y penal para toda clase de personas y delincuentes" 46 .

El artículo 32 No 2 de la Constitución de Honduras, de 1825, declaraba como atribución de la Asamblea del Estado: "Formar el código civil y el criminal [...]"47, disposición repetida después por el artículo 42 No 2 de la Constitución de $1831^{48}$; el artículo 29 No 2 de la Constitución de 1848, dictada por Honduras bajo el imperio teórico de la Confederación Centroamericana, a su vez, señalaba corresponder al Poder Legislativo: "[...] decretar los códigos civil, criminal y de procedimientos, para toda clase de personas $y$ delincuentes" ${ }^{49}$. El artículo 26 No 4 de la Constitución de 1865 disponía que el Poder Legislativo podía delegar en el Ejecutivo la facultad de "Decretar los códigos civil, penal, de procedimientos, de comercio y minería" 50 ; lo que fue repetido por el artículo 26 No 4 de la Constitución de $1873^{51}$.

En el Uruguay, por su lado, el artículo 17 No 1 de su Constitución de 1830, la primera de ese país, decía competer a la

\footnotetext{
45 En Gallardo, Ricardo (1961) Las constituciones de El Salvador (Madrid, Ediciones Cultura Hispánica) p. 303.

46 Gallardo (1961) p. 320.

47 En Mariñas Otero, Luis (1962): Las Constituciones de Honduras (Madrid, Ediciones Cultura Hispánica) p. 58.

48 Mariñas Otero (1962) p. 77

49 Mariñas Otero (1962) p. 123.

50 Mariñas Otero (1962) p. 152.

51 Mariñas Otero (1962) p. 181; pero este texto decía "promover" en vez de "decretar".
} 
Asamblea General: "Formar y mandar publicar los códigos" 52 .

La Constitución ecuatoriana de 1830 , llamada de Riobamba, por el lugar de su emisión, en su artículo 26 No 11 imponía al Congreso la obligación de: "Formar el código de leyes civiles" 53 . El artículo 43 No 14 de la Constitución de 1835 dijo que era atribución de aquel organismo: "Formar los códigos nacionales" "54; lo que fue repetido por los artículos 37 No 13 de la Constitución de $1843^{55}$; 42 No 18 , de la de $1845^{56} ; 31$ No 29 , de la de $1851^{57}$; y 4 No 18 de la de $1852^{58}$.

En Bolivia, el artículo 43 No 1 de la Constitución de 1831 señalaba como atribución del Senado: "Formar los códigos civil, penal, de procedimientos, de minería y de comercio"59. La Constitución de 1834, en su artículo 44 № 1 , prescribió más escuetamente que el Senado tiene la iniciativa "En la formación de los códigos civil, penal, de procedimientos, de minería y de comercio" 60 , aunque aprobarlos era función de las dos cámaras que establecía esa constitución ${ }^{61}$.

En la Argentina, el artículo 64 No 11 de la Constitución Nacional de 1853,

\footnotetext{
52 En Gros Espiell, Héctor (1951): Las Constituciones del Uruguay (Madrid, Ediciones Cultura Hispánica) p. 151.

53 En BorJa, Ramiro (1951): Las constituciones del Ecuador (Madrid, Ediciones Cultura Hispánica) p. 111.

54 Borja (1951) p. 135.

55 BORJa (1951) p. 162.

56 BorJa (1951) p. 197.

57 Borja (1951) p. 231: en la fórmula se varió "formar" por "dar", y la atribución quedó referida a una Asamblea Nacional, como se llamó ahora al órgano parlamentario.

58 Borja (1951) p. 269: aquí se volvió a la fórmula y al órgano tradicionales de 1835.

59 En Trigo, Ciro (1958): Las constituciones de Bolivia (Madrid, Ediciones Cultura Hispánica) p. 207.

60 Trigo (1958) p. 231.

61 Trigo (1958) p. 256.
}

dispuso que fuera atribución del Congreso "Dictar los códigos civil, comercial, penal y de minería [...]"62; lo que hubo de ser repetido por el artículo 67 No 11 de la Constitución de $1869^{63}$

Aunque fuera de Iberoamérica, debe hacerse presente que en Haití, ya su Constitución Imperial de 1805 contenía un artículo 18, que decía "Se publicará un Código penal que deberá ser severamente observado"64; y la de 1816, un artículo 37, que rezaba: "Se redactarán códigos civiles, penales, de procedimiento y de comercio comunes a toda la República"65; pero estas normas, por cierto, se hacían directamente eco de la tradición constitucional francesa que antes vimos.

Este recuento de casos nos muestra que la idea de incluir en la Constitución un programa de reforma de la legislación bajo la forma de códigos fue constante y reiterada en el constitucionalismo hispanoamericano decimonónico posterior a la carta de Cádiz. Por lo demás, ya hemos visto que apareció ahí antes de esta, aunque limitadamente a Nueva Granada; y, más débilmente, en Chile y en Venezuela.

Si nos preguntamos de dónde pudo salir la idea de incluir en el texto constitucional mismo un programa de reforma legislativa bajo la forma de codificación, la respuesta la conocemos: de alguna constitución francesa, con más verosimilitud de la de 1791; de la Constitución de Bayona de 1808; o de la de Cádiz.

62 En Legón, Faustino-Medrano, Samuel (1953): Las constituciones de la República Argentina (Madrid, Ediciones Cultura Hispánica) p. 421.

63 Legón y Medrano (1953) p. 450.

64 En Mariñas Otero, Luis (1968): Las Constituciones de Haití (Madrid, Ediciones Cultura Hispánica) p. 128.

65 Mariñas Otero (1968) p. 165. 